None of them desired to imbibe Niagara, or are likely to forget Lord Kelvin. Amongst them there was the deepest feeling of gratitude for the hospitality they received; hospitality which the most distinguished acknowledged was more kindly and more lavish than they had any right either to expect or to desire.

\section{THE HABITS OF ICE-SEALS.}

THERE are four species of earless, or true seals inhabiting the boreal part of the North Atlantic and Arctic Oceans which may well be designated ice-seals, since they dwell for a considerable portion of the year either on the solid pack-ice or on ice-floes. These species are the Greenland or harp-seal (Phoca granlandica), often termed, on account of the conspicuous black markings on the yellowish-white ground-colour of the back, the saddle-back; the ringed seal ( $P$. hispida); the large bearded seal, or square-flipper ( $P$. barbata); and the crested, or hooded seal (Cystophora cristata), the males of which carry the peculiar dilatable sac on the nose from which the species derives its names. The first three of these are closely allied forms, but it is not a little remarkable that whenever the young of the first and second are born in a uniform yellowish-white coat, those of the third make their appearance in the world in a dark pélage ; the white coat being not improbably shed in utero. It is commonly believed that the young of the fourth species are also white-coated, as are certainly those of the more southern grey seal (Halicharus grypus). If a white coat serves as a protection to the new-born "pup" on the ice, it is difficult to see why this type of coloration should have been departed from in the case of one species. But the whole subject is one of great difficulty, as the white-coated young of the grey seal may often be seen in the Hebrides reposing on black rocks. All the four species in question agree in the circumstance that the young are produced during their sojourn on the ice; but in other respects very considerable differences are displayed in regard to habits.

In the first place, the Greenland and the crested seal are essentially migratory animals, the former associating in immense herds and the latter in smaller parties, whereas the bearded seal, which is considerably the largest of the three, only makes a slight movement to the south when compelled by the increase of the winter pack-ice, and is a comparatively solitary creature. But these are by no means the only points of difference in this respect. The Greenland seal visits the country from which it takes its name twice annually, namely in the autumn and the spring; and breeds chiefly on the coasts of Jan-Mayen and Newfoundland, the young being produced in the latter district at the beginning of March, but in the former some weeks later. That some of these seals which migrate from Greenland travel westwards to Jan-Mayen is most probable, but where the remainder pass their time while away from their native land, is not yet ascertained with certainty. The southern migration of these seals on the Atlantic coast of America, which commences when the frost sets in, is described as a wonderful sight; at first small advance parties pass down, and these are followed by the main body, which includes thousands of individuals, and takes about a couple of days in passing a given point. Although during their migration hugging the coasts, the Greenland seals during the breeding-season frequent the heavy floe-ice, at least in East Greenland, which is not liable to break up, and therefore affords them a safe habitation. As they have no difficulty in obtaining access to the water, in this district, at any rate, they do not make breathing-holes; and it has been commonly supposed that this is their invariable habit, but in a little

$$
\text { NO. I } 476 \text {, vOL. } 57.7
$$

pamphlet recently issued by Commander Robinson, ${ }^{1}$ entitled "Ice-riding Pinnipeds," it is stated that when on solid thin ice such holes are made. In disposition this seal is mild and gentle ; and it is a well-ascertained fact that the young are born in the white coat, the British Museum possessing a stuffed example in this state. From its numerical abundance it is commercially one of the most valuable of the true seals.

As regards the bearded seal, this, as already mentioned, is a comparatively rare and solitary species, fond of reposing on floating ice in the open sea, and moving southwards only when compelled by the extension of the pack-ice. It is apparently one of the species which does not make a breathing-hole, as it does not frequent large extents of ice ; and it may generally be recognised at a distance by its habit of performing a somersault when diving into the water. In the pamphlet already referred to the suggestion is made that a certain number of the young of this species are infected by the migratory instinct of the young Greenland seals, and wander south with them. In addition to the testimony of sealers, a specimen in the Natural History Museum conclusively proves that the young "square-flipper" is born in the dark coat.

The ringed seal, which is common to the North Atlantic and Pacific, is a non-migratory species, whose favourite haunts are retired fjords and bays, in which it remains during the time they are tightly packed with ice. When, however, the ice breaks up, the "floe-rats," as they are called by the sealers, retire to the ice-floes, upon which the young are born in March and April. This species always form an "atluk," or breathing-hole in the ice, which is in the form of an oblique passage, through which the surface of the ice can easily be reached from below. The hole appears to be made while the ice is forming; but accurate accounts of the modus operandi are still required. In the above-mentioned pamphlet it is stated that the animal works on the ice with its front claws, revolving round this pivot with its body ; but it is somewhat difficult to realise how such a method can be effectual, and, prima facie, it would seem more probable that the passage is made while the ice is sufficiently thin to break with the weight of the seal, and kept open by constant use. The breathing-hole affords an easy method of capturing the seals which use it, and the great reduction in the number of these seals is largely due to this method of hunting.

As it differs much in external form from other iceseals, so the crested seal has several peculiarities in habits. Unlike the others, it is a bad-tempered animal, living, except when driven to associate more closely by an unusual scarcity of ice, in small parties scattered over a wide extent of ice, always preferring the outside of the pack, or drift ice to the neighbourhood of land, and seldom frequenting either the coasts or isolated rocks. On the American side they are chiefly to be met with near the eastern edge of the main ice-pack, where there are numerous patches of open water, and consequently abundant room for fishing. Ordinarily small parties of from three to five individuals are scattered over the broken rough ice, at distances of from thirty to fifty yards apart. The easy access to water thus afforded obviates in general the necessity of making breathingholes. They are stated to resemble fur-seals in being polygamous; and the males certainly engage in combats for the possession of the females, during which they utter loud cries which may be heard for miles. In winter these seals travel south, but they do not make the two annual journeys characteristic of the saddle-backs in Greenland. In European seas the crested seal has become comparatively rare, although on the American

1 I am informed by the author that, owing to certain errors, all available copies of this work have been cancelled. 
side, where its favourite haunts are Labrador and Newfoundland, it is still so abundant that many thousands are at times taken by a single vessel. March is the breedingtime, and at this season the young are produced on the ice far away from land. All previous writers with which we are acquainted state that the young are born in the white coat, which is not exchanged for the grey till the lapse of about twelve months. But Commander Robinson is positive that this is incorrect, and that the grey coat is assumed previous to birth. Unfortunately there are no specimens in the British Museum available for deciding this disputed point ; but it is earnestly to be hoped that such may be supplied before long. In the meantime it may be suggested that the discrepancy has arisen from the young of one species having been mistaken for that of another, although it is at the same time difficult to see how this can have been the case with a seal so peculiar in appearance, and dwelling so much apart as does the present.

The above are but a few of the leading features in the habits of the northern ice-seals, to describe which in detail would require a small volume. Among the points which require special elucidation are what becomes of the great bulk of the harp-seals between their visits to Greenland in May and September, the mode in which scals make their breathing-holes, and the colour of the newly-born crested seal.

R. L.

\section{MAGNETIC AND PENDULUM} OBSER VATIONS. ${ }^{1}$

$\mathrm{I}^{\mathrm{T}}$ may be remembered that Lieutenant Peary, before starting on his sixth expedition to Greenland in 1896 , offered transport on his steamer to two parties of scientific men, and that the opportunity was very properly accepted. The parties--which were under the direction respectively of Prof. A. E. Burton, of the Massachusetts Institute of Technology, and Prof. R. S. Tarr, of Cornell University-consisted each of six members, and were entirely independent in organisation and equipment of the main body of the expedition. The researches of the Boston party consist of observations in terrestrial physics, including glacier phenomena, and studies of Eskimo life, and their reports are now coming to hand. The report of Mr. G. R. Putnam, of the United States Coast and Geodetic Survey, who undertook the magnetic and pendulum observations, is now before us.

Early in July Mr. Putnam left Boston with a complete outfit of magnetic, pendulum, and astronomical instruments, and arrived at Halifax, Nova Scotia, two days later. Here he found time to make magnetic determinations at the Naval Dockyard, at which station the declination observations cover a period of nearly three centuries. Reaching Sydney, Cape Breton, the starting point of the expedition proper, six days elapsed before the departure of the Hope, Lieutenant Peary's steamer, and in this time all the instruments were set up and used. The voyage along the Labrador coast was only interrupted by a few hours' stop at Turnavik, where magnetic observations were made. Passing up the Hudson Straits, Mr. Putnam spent two days at Ashe Inlet, but here a gale on the second night unfortunately interfered with the full success of his work. The Hope then turned eastward, and on August $I$ the coast of Greenland was sighted. Magnetic observations only were made at Godhavn, and Umanak was reached a day or two after. Here Mr. Putnam's party landed and settled down for a month, while the Hope continued her northern voyage. The required observations having been completed, the whole party indulged in exploring

1 "The Scientific Work of the Boston Party on the Sixth Peary Expedition to Greenland. Report A."

No. I 476 , vOL. 57$]$ trips, but on these excursions they could not well take the magnetic instruments. On the return of Lieutenant Peary, the homeward journey began. After the magnetic observations at Godhavn had been repeated, the ship anchored at Niantilik, in Cumberland Sound, where observations were again attempted, but here the value of the pendulum observations was lessened, because unfavourable weather did not allow the necessary timeobservations. Sydney was again reached September 26, and here a few observations were taken, prior to the instruments being shipped to Washington, where they were tested and found to be unaffected by their long journey of 5000 miles.

The magnetic outfit, comprising a dip circle of the ordinary Kew pattern and a magnetometer, was lent by the Coast and Geodetic Survey. In the case of the latter instrument, the magnet consisted of a hollow octagonal prism of steel, held in a stirrup with a long arm to which the two silk fibres were attached. By this arrangement the magnet remained sensibly horizontal at ordinary latitudes, but a copper balancing ring was sometimes used at the most northerly stations. The formula used for computing the moment of inertia of this ring (p.74) is incorrect, and the term $\frac{1}{3}\left(x_{2}^{2}+x_{2} x_{1}+x_{1}^{2}\right)$ should be replaced by $\frac{1}{4}\left(x_{2}+x_{1}\right)^{2}$, although the numerical correction happens to be insensible. For determining the azimuth by the sun, the magnet box is removed from the base and circle, and the latter is then used with a separate theodolite.

Mr. Putnam's results in this part of his work are both valuable and interesting. Further evidence has been obtained of the violence of magnetic disturbances in polar regions, although far greater disturbances have been recorded. Thus the range in a day observed at Niantilik exceeded $4 \frac{1}{2}$ degrees, a change of over 3 degrees being noticed in twenty minutes. A comparison with the contemporary record at Washington reveals, it is true, that an unusual magnetic storm visited this city, but its severity as measured by the range of declination was fifteen times less than that at the northern station. With the exception of Niantilik, earlier information is available with regard to all the stations visited by Mr. Putnam; and although only Halifax and Godhavn possess satisfactory records extending over the last three-quarters of a century, the general tendency in the change of the magnetic elements seems to be clearly indicated. At present it appears that at all these points "the westerly declination is diminishing, the northerly dip is diminishing, the horizontal force is increasing, and the total force is diminishing."

The apparatus used for determining the relative force of gravity, comprised a set of three half-second pendulums, one sidereal and two mean time chronometers, and a meridian telescope. The pendulums were swung in an air-tight case, in which the pressure was reduced to about $6 \mathrm{~cm}$. by means of an air-pump. All the chronometers were provided with electrical break circuit attachments, and were thus capable of the instantaneous raising of a shutter by an electrical mechanism and the momentary illumination of a slit every second or two seconds. By this means the reflections of a flash in two mirrors, one attached to the fixed knife edge, and the other to the head of the pendulum, could be observed in a telescope. The period of the pendulum was then deduced from the observed coincidences. At the southern stations coincidences were observed with sidereal seconds, but nearer the pole, with mean time seconds, on account of the decrease in the period of the pendulum. Whenever the plan could be carried out each pendulum was swung for: a period of eight hours, both in reversed and direct positions, and star observations were made at the beginning and end of the forty-eight hours. The following table summarises the principal results (p. 103):- 